\title{
What Can Instructors Focus on When Improving Undergraduate Science Experiments? Supporting a Cross- Disciplinary Approach
}

\author{
Alexandra Yeung ${ }^{\mathrm{a}}, \mathrm{Scott}_{\text {Cornish }^{\mathrm{b}}}, \mathrm{Scott}_{\mathrm{Kable}^{\mathrm{c}}}$ and Manjula Sharma ${ }^{\mathrm{b}}$ \\ Corresponding author: Scott Cornish (cornish@physics.usyd.edu.au) \\ ${ }^{a}$ Faculty of Science and Engineering, Curtin University, WA, 6102, Australia \\ ${ }^{\mathrm{b}}$ School of Physics, The University of Sydney, Sydney, NSW, 2006, Australia \\ ${ }^{c}$ School of Chemistry, University of New South Wales, Kensington, NSW, 2052, Australia
}

Keywords: undergraduate laboratory teaching, surveying laboratory programs, evaluating laboratory teaching, learning in science labs

International Journal of Innovation in Science and Mathematics Education, 27(3), 25-40, 2019

\begin{abstract}
For nearly two decades, the Australian national project Advancing Science and Engineering through Laboratory Learning (ASELL), has been using an evidence based approach to improve undergraduate experiments. This paper presents the ASELL Students Laboratory Experience (ASLE) survey, administered to 2691 students in five disciplines: biochemistry, biology, chemistry, physics, and pharmacology. The 14 item survey probes students' perceptions of an experiment, practical or fieldwork. An exploratory factor analysis extracted two factors, 'experiment-based motivators' and 'course-level resources', and both factors correlate well with 'overall' learning experiences. Each survey item was also compared to the 'overall' learning experiences of the experiment, revealing the most critical elements of each experiment. The implications of this analysis, for practitioners is that the survey items in the 'course-level resources' taper off indicating that after an optimum value, further investment in these aspects do not necessarily influence student perceptions of their learning experiences. On the other hand, the survey items in the 'experiment-based motivators' behave differently in that they do not taper off indicating that further investment can influence experiences. How these factors relate to the overall experience suggest they correspond to the well-known two-factor theory of motivation.
\end{abstract}

\section{Introduction}

There is a long tradition of experimental, practical and field work in undergraduate science education. However, there is a tendency to brand lab based teaching as static, out dated, and no longer of use to students who enter work places which may not require experimentation (Rice, Thomas, \& O'Toole, 2009). Others suggest that practical activities fall short on enhancing student learning with understanding (Hofstein \& Lunetta, 1982). On the other hand, surveys of employers' consistently point to skills learnt within the practical component as valued and suggest further development of these skills during undergraduate science education (Sharma, Mills, Mendez, \& Pollard, 2005; Harris, 2012; Royal Australian Chemical Institute, 2005).

A focus to provide a good learning experience, develop skills and facilitate laboratory learning is seen across the different science disciplines. However, there is a lack of research on undergraduate experimental work across different science disciplines, including efforts to 
evaluate or compare evaluations across different science disciplines. While instructors in their own disciplines can strive to evaluate and improve experiments, if common features exist and can be identified, then the various disciplines could collectively address issues, and crossdisciplinary initiatives could be implemented at Faculty and Institutional levels.

The complexity of measuring laboratory learning is compounded by the fact that objectives of experimental work encompass procedural knowledge, conceptual understanding, and process/inquiry skills. These various goals of laboratory learning have been articulated by many (Boud, Dunn, \& Hegarty-Hazel, 1986; Hart, Mulhall, Berry, Loughran, Gunstone, 2000; Abrahams \& Millar, 2008; Hofstein \& Lunetta, 2004; Hofstein \& Mamlok-Naaman, 2007, Membiela \& Vidal, 2017). The difficulty of encompassing all these factors has made these kind of measurements rare. Measures include assessing what students have learnt (learning outcomes measures) and evaluating student perceptions of their learning experiences (Beck \& Blumer, 2016; Richardson, Sharma, \& Khachan, 2008; Weston \& Laursen, 2015). There is no doubt that both are important as each serves a particular purpose, but both are difficult to measure. This paper aims to shed light on the latter by;

1. Implementing the 14 item ASELL Students Laboratory Experience (ASLE) survey across 5 disciplines, biochemistry, biology, chemistry, pharmacology and physics involving 2961 students and identifying the underlying factors using Exploratory Factor Analysis.

2. Correlating the underlying factors, as well as individual survey items with students' perceptions of their overall learning experiences, to provide insight into what instructors can do to improve their experiments.

3. Reflecting on the connection between the factors identified in this study and the dual factor theory of Herzberg (1968).

We draw on the 'motivation-hygiene' theory (Herzberg, 1968) as an interpretive framework to extract 'take-home messages' for instructors. Bassett-Jones and Lloyd (2005) argue that the 'motivation-hygiene' theory has utility for practitioners and managers. According to the 'motivation-hygiene' dual factor theory, the nature of work flagged in the survey items in the motivation factor correlates positively with satisfaction and competency. Examples of survey items the Herzberg identified in the motivation factor are; achievement, responsibility and the work itself. Hence, if practitioners intend to increase satisfaction, then they should focus on those aspects. The theory also articulates that the nature of the survey items in the hygiene factor are related to dissatisfaction rather than satisfaction. Some survey items that Herzberg identified in the hygiene factor are; company policy administration, relationship with supervisors/peers and work conditions. Herzberg (1968) suggests that there is excessive focus on improving the hygiene factor survey items, at the cost of the motivators. In other words, when the hygiene factors have reached an adequate value, dissatisfaction is avoided. However, further investment in hygiene survey items does not necessarily result in increased satisfaction. In general, the motivation factor is related to achievement, competency and responsibility, while the maintenance factor is related to the environment, procedures and supervision. In this study, we probe whether 'motivation-hygiene' theory emerges in students' experiences of undergraduate science experiments.

To discern students' perceptions of undergraduate experiments detailed 'contextual' data of the experiment, such as associated assessment outcomes and how the experiment contributes to the course content is helpful, but it is possible that it is not necessary. While it is worthy to explore detailed data on the type of experiment, for example, open-inquiry experiments, it is 
beyond the scope of this study. By using an exploratory factor analysis, we aim to identify the factors that influence students' laboratory learning experiences. Also of interest is how the survey items relate to the 'overall' experiences and if there is a way to differentiate the survey items as either motivators or hygiene survey items. In short, in this study, we look at a wide range of existing experiments without detailed data on their content. Teachers can compare their own experiments with many others that span across many contexts and disciplines. This can give teachers information complementary to more detailed 'case studies'.

\section{Implementing the ASLE survey across five science disciplines}

\section{The ASLE survey for multiple science disciplines}

Advancing Science and Engineering through Laboratory Learning (ASELL) is an Australian national project that has operated for nearly two decades (Yeung, et al., 2011). ASELL uses an evidence based approach to improve undergraduate science laboratory experiments. Numerous survey instruments have been developed and validated in this endeavour. This paper extends one such survey, the ASELL Student Laboratory Experience, ASLE, which has been validated and implemented with 3153 chemistry students (Barrie et al., 2015) to five different disciplines

The ASLE survey is designed to be administered immediately after students have completed an experiment in the laboratory or as part of fieldwork. By necessity, the instrument is brief as students are usually tired and want to leave. The intent is to capture student perceptions of their experiences. Survey items sought to capture whether the experiment was interesting, whether it helped develop lab skills and whether it increased understanding of the discipline. There are also survey items on various skills, from teamwork and data interpretation to responsibility for own learning. Some survey items are associated with the course; demonstrators, background information for each experiment, assessment and expected learning outcomes. The final survey item is students' self-reporting on 'overall learning experience' and is used to compare the factors and survey items with the previous study by Barrie et al. (2015).

The ASLE has fourteen questions asking students to respond to a Likert scale with the options Strongly Disagree, Disagree, Neutral, Agree, and Strongly Agree. Table 1 shows the survey items on the ASLE survey. The development of ASLE involved three cycles of implementation, validation and Delphi style consultation (Barrie et al 2015). The current study introduced another two cycles, the fourth and fifth cycle, to extend the survey into multiple science disciplines. The fourth cycle was Delphi style consultation with disciplinary based education experts from different science disciplines. These experts were volunteers who had previous involvement with the ASELL program. They made suggestions in conversation with the survey designers, and via correspondence. Their suggestions fell into three categories:

1. Make only three changes, (1) use the specific name of the discipline the survey is used in, (2) insert 'in this experiment' or 'name of experiment' to make the ASLE particular to an experiment and (3) use local terms such as tutor, demonstrator or teaching assistant.

2. Insert new discipline specific survey items e.g. safety in chemistry, ethics in biology, and specifically refer to longer projects and field-work.

3. Maintain the intent but change wording of some survey items to make their meaning more obvious.

The suggestions from category 1 were implemented. Those from category 2 were proposed as additional survey items for each discipline to insert, but would not form the core set of survey items common to all disciplines. Those from category 3 were used to change phrasing and 
discern if the meaning could indeed become clearer.

In the fifth cycle, the survey was workshopped amongst a broad range of disciplines, and trialled with students. At the next meeting it was agreed that the core set of questions had utility and would be retained. The conclusion reached was that the changes suggested from category 1 would be incorporated, those from 2 would be optional, and category 3 made no difference. The ASLE for the science disciplines is shown in Table 1.

\section{Table 1: The ASLE instrument and how it is scored.}

Scoring (a) - items 1 to 12 , were scored as +2 (strongly agree) to -2 (strongly disagree), with a 0 (neutral) midpoint. Scoring (b) - item 13, a +2 (way too much) to -2 (nowhere near enough), with a 0 (about right) midpoint. Scoring (c) - item 14, a +2 (excellent) to -2 (very poor) scale has been used, with a 0 (average) midpoint. Published with permission from Barrie et al (2015)

\begin{tabular}{|c|c|c|}
\hline Full Survey Item & Short Name & Scoring \\
\hline $\begin{array}{l}\text { 1. This [experiment] helped me to develop my data interpretation } \\
\text { skills }\end{array}$ & $\begin{array}{l}\text { Data interpretation } \\
\text { skills }\end{array}$ & (a) \\
\hline 2. This [experiment] helped me to develop my laboratory skills & Laboratory skills & (a) \\
\hline 3. I found this to be an interesting [experiment] & Interest & (a) \\
\hline 4. It was clear to me how this [laboratory exercise] would be assessed & Clear assessment & (a) \\
\hline $\begin{array}{l}\text { 5. It was clear to me what was expected to learn from completing this } \\
\text { [experiment] }\end{array}$ & $\begin{array}{l}\text { Clear learning } \\
\text { expectations }\end{array}$ & (a) \\
\hline $\begin{array}{l}\text { 6. Completing this experiment has increased my understanding of } \\
\text { [discipline] }\end{array}$ & $\begin{array}{l}\text { Increased } \\
\text { understanding }\end{array}$ & (a) \\
\hline $\begin{array}{l}\text { 7. Sufficient background information, of an appropriate standard, is } \\
\text { provided in the introduction }\end{array}$ & $\begin{array}{l}\text { Background } \\
\text { material }\end{array}$ & (a) \\
\hline 8. The [demonstrators] offered effective supervision and guidance & Demonstrators & (a) \\
\hline $\begin{array}{l}\text { 9. The [experimental procedure] was clearly explained in the lab } \\
\text { manual or notes }\end{array}$ & Laboratory notes & (a) \\
\hline $\begin{array}{l}\text { 10. I can see the relevance of this [experiment] to my [discipline] } \\
\text { studies }\end{array}$ & Relevance & (a) \\
\hline 11. Working in team to complete this [experiment] was beneficial & Teamwork & (a) \\
\hline $\begin{array}{l}\text { 12. The [experiment] provided me with the opportunity to take } \\
\text { responsibility for my own learning }\end{array}$ & Own learning & (a) \\
\hline 13. I found that the time available to complete this [experiment] was & Time & (b) \\
\hline 14. Overall, as a learning experience, I would rate this [experiment] as & Overall & (c) \\
\hline \multicolumn{3}{|l|}{ Open-ended questions } \\
\hline \multicolumn{3}{|l|}{ 15. Did you enjoy doing the experiment? Why or why not? } \\
\hline \multicolumn{3}{|l|}{ 16. What did you think was the main lesson to be learnt from the experiment? } \\
\hline \multicolumn{3}{|c|}{ 17. What aspects of the experiment did you find most enjoyable and interesting? } \\
\hline \multicolumn{3}{|c|}{ 18. What aspects of the experiment need improvement and what changes would you suggest? } \\
\hline 19. Please provide any additional comments on this experiment here & & \\
\hline
\end{tabular}

Notes: Scales used: (a) A = 'strongly agree', B='agree', C='neither agree nor disagree',

$\mathrm{D}=$ 'disagree', E='strongly disagree'; (b) A = 'way too much', $\mathrm{B}=$ 'too much', $\mathrm{C}=$ 'about right',

$\mathrm{D}=$ 'not enough', E='nowhere near enough'; (c) A = 'excellent', B='good', C='average',

$\mathrm{D}=$ 'poor', E='very poor'.

Words in square brackets could be changed to suit the laboratory, discipline or country context. The short name is used in the text to refer to survey items, which are responded to on the five-point scale indicated. 


\section{Data collection and analysis}

Data collection protocols were approved by The University of Sydney Human Ethics Committee. The undergraduate students were given necessary information regarding completing the survey at the beginning of the session. At the end of the session, a laboratory demonstrator/tutor (TA) administered the survey. The surveys were anonymous and voluntary; the only identifying feature was the experiment under evaluation, and the Unit of Study (course) undertaken by the student. The surveys were posted back to The University of Sydney where the data was entered and processed. The data and summary graphs were sent back to the home institutions. A summary of the dataset in this paper is shown in Table 2. Response and completion rates for the surveys were excellent being $>90 \%$ and $>80 \%$ respectively.

Table 2: Summary of the dataset. KMO and Bartlett's tests are adequate.

\begin{tabular}{|l|l|l|l|l|l|}
\hline Discipline & $\begin{array}{l}\text { No of } \\
\text { experiments }\end{array}$ & $\begin{array}{l}\text { No of } \\
\text { institutions }\end{array}$ & $\begin{array}{l}\text { No of } \\
\text { Students }\end{array}$ & $\begin{array}{l}\text { KMO } \\
\text { measure of } \\
\text { sampling } \\
\text { adequacy }\end{array}$ & $\begin{array}{l}\text { Bartlett's } \\
\text { test of } \\
\text { sphericity }\end{array}$ \\
\hline Biochemistry & 1 & 1 & 191 & .876 & $\mathrm{P}<0.001$ \\
\hline Biology & 8 & 6 & 1027 & .884 & $\mathrm{P}<0.001$ \\
\hline Chemistry & 6 & 4 & 827 & .932 & $\mathrm{P}<0.001$ \\
\hline Pharmacology & 1 & 1 & 163 & .860 & $\mathrm{P}<0.001$ \\
\hline Physics & 7 & 4 & 483 & .924 & $\mathrm{P}<0.001$ \\
\hline TOTAL & $\mathbf{2 3}$ & $\mathbf{1 6}$ & $\mathbf{2 6 9 1}$ & $\mathbf{. 9 2 5}$ & $\mathbf{P}<\mathbf{0 . 0 0 1}$ \\
\hline
\end{tabular}

The data were entered into EXCEL and analysed using SPSS. The factor analysis used a principal component analysis (PCA) method with a Varimax rotation and Kaiser Normalisation (Kaiser, 1958); the typical method in this type of study as it is considered the standard for orthogonal rotations, enforcing uncorrelated factors. As such there is a clear interpretation of the extracted factors and there is no theoretical reason to expect the factors to be correlated. Other alternative rotation methods were examined, but provided no discernible difference in the results. Normality and Bartlett's test for sphericity were checked, as was multicollinearity as per Field, 2000, see Table 2. In all respects, the data satisfied the criteria and were adequate for PCA. Since we are interpreting using the 'motivation-hygiene' theory, it is prudent to identify factors across disciplines and the behaviour of those factors and the constituent survey items. The formalisation of latent variables using Confirmatory Factor Analysis is not needed for the intended interpretative framework, making it beyond the scope of this study.

Scree plots of the eigenvalues of the whole dataset as well as for each discipline clearly indicated a two factor solution. Three survey items were omitted from the factor analysis, Q14 'Overall' as it was a summary item, Q11 'Teamwork' and Q13 'Time' because they appeared as separate survey items, always loading by themselves. These survey items are useful because they probe important aspects of the laboratory environment for the practitioner to consider; they have been retained in the discussion of results.

\section{The two factors: Experiment-based motivators and course-level resources}

Table 3 presents the data with the two factor solution, including reliability measures. Cronbach's alpha and McDonalds omega were used as measures of reliability. George and 
Mallery (2003), provide a guide for interpreting Cronbach's alpha as follows: " $>.9$ - Excellent, $>.8$ - Good, > .7 - Acceptable, > .6-Questionable, > .5 - Poor, and < .5- Unacceptable" (p. 231). The reliabilities for each factor fall in the good range. In addition to Cronbach's alpha, the consistency of the factors was also estimated by using McDonald's omega. This measure was chosen as Macdonald's omega is more applicable when the elements of the factor describe more than one construct (Dunn, Baguley \& Brunsden, 2014). In this study the factors are groups of survey items that do not clearly relate to a single construct, for example, 'interest in experiment' and 'lab skills'.

Table 3: Summary of factor loadings for two factor solution.

Small cross-loading with $0.35<\lambda<0.5$ are marked with an ' $\mathrm{X}$ '. Factor 1 is named 'experiment-based motivators', and factor 2 - is named 'course-level resources'

\begin{tabular}{|l|c|c|}
\hline & 1 & 2 \\
\hline 2. Laboratory skills & .771 & \\
1. Data interpretation & .734 & \\
6. Increased understanding of discipline & .689 & \\
3. Interest in experiment & .687 & \\
12. Responsibility for own learning & .614 & \\
10. Relevance of experiment to discipline & .606 & $X$ \\
7. Background material & & .766 \\
9. Laboratory notes & & .759 \\
8. Demonstrator supervision & & .642 \\
4. Clear assessment guidelines & & .661 \\
5. Clear learning expectations & $X$ & .601 \\
\hline CB alpha & 0.84 & 0.80 \\
\hline MD omega & 0.84 & 0.82 \\
\hline
\end{tabular}

There are four or more survey items in each factor with a clear loading on only one factor. Each factor has only one small cross correlating survey item, making this a robust result, see Field (2000). The survey items that make up each factor do follow a pattern. The survey items of the first factor are specific to individual experiments. Some of these are obviously specific to the experiment, such as 'laboratory skills', 'data interpretation', 'interest in experiment', and 'relevance of experiment to discipline'. These survey items will clearly be different for different experiments. The others are less obvious; 'increased understanding of discipline' is related specifically to the experiment, as not all experiments will be equally related to the topics being studied within the coursework. It is often the case that the topics covered by lectures and labs are different, or are not taught synchronously. The survey item 'responsibility for own learning' is also highly dependent on how the specific experiment is presented to students, such as the level of student direction that is allowed in the experiment. On this conceptual basis, the name of this factor is 'experiment-based motivators'.

The survey items of the second factor do not necessarily vary with the experiment but rather are related to the overall course, and so named 'course-level resources'. These survey items are associated with the structure and design of the course and are likely to not vary significantly between experiments within a laboratory program. For example 'clear assessment guidelines', and 'clear learning expectations', are survey items that would normally follow a format 
specified by the course. Both are highly dependent on the students' perceptions of the learning outcomes and assessment of the course. How well the assessment guidelines are received by students is dependent on their individual engagement with the course (see for example Burgess, Yeung and Sharma, 2015). This is also true for 'background material', which is couched within the other coursework such as lectures. The perceived quality of 'demonstrator supervision' and 'laboratory notes' are also likely to be fairly consistent for students across all experiments.

The two factor solution was also explored for the individual disciplines, the results are given in Table 4. In general there was a remarkable similarity in the grouping of survey items across all the disciplines. The observation that these factors persist across the disciplines is strong evidence for the validity and robustness of the two factor solution. There are only three survey items, two from physics and one from biochemistry which load into a different factor. These need further investigation, but for the purpose of this study, the factors still retain sufficient survey items and are adequately robust to persist with ascertaining the utility of ASLE for practitioners.

Table 4: Summary of factor loadings, separated by discipline. Small cross-loading with $0.35<\lambda<0.5$ are marked with an ' $\mathrm{X}$ '. Factor 1 is named 'experiment-based motivators', and factor $2-$ is named 'course-level resources'

\begin{tabular}{|c|c|c|c|c|c|c|c|c|c|c|}
\hline & \multicolumn{2}{|c|}{ Chemistry } & \multicolumn{2}{|c|}{ Biology } & \multicolumn{2}{|c|}{ Biochemistry } & \multicolumn{2}{|c|}{ Physics } & \multicolumn{2}{|c|}{ Pharmacology } \\
\hline & 1 & 2 & 1 & 2 & 1 & 2 & 1 & 2 & 1 & 2 \\
\hline 2. Laboratory skills & .811 & & .724 & & .696 & & .835 & & .720 & \\
\hline 1. Data interpretation & .759 & & .710 & & 697 & & .748 & & .686 & \\
\hline 6. Increased & & & & & & & & & & \\
\hline understanding of & .705 & $\mathrm{x}$ & .659 & & 821 & & .549 & .529 & 686 & \\
\hline 3. Interest in experiment & .710 & $\mathrm{x}$ & .656 & & 797 & & $\mathrm{x}$ & .606 & .778 & \\
\hline $\begin{array}{l}\text { 12. Responsibility for own } \\
\text { learning }\end{array}$ & .704 & & .549 & & $\mathrm{x}$ & $\mathrm{x}$ & .588 & $\mathrm{x}$ & .515 & \\
\hline $\begin{array}{l}\text { 10. Relevance of } \\
\text { experiment to discipline }\end{array}$ & .601 & $\mathrm{x}$ & .570 & $x$ & .755 & & .610 & $\mathrm{x}$ & .543 & $\mathrm{x}$ \\
\hline 7. Background material & & .824 & & .737 & & .690 & & .653 & & .807 \\
\hline 9. Laboratory notes & & .844 & & .685 & & .712 & & .681 & & $\mathrm{x}$ \\
\hline $\begin{array}{l}\text { 8. Demonstrator } \\
\text { supervision }\end{array}$ & $\mathrm{x}$ & .638 & & .641 & & .606 & & .674 & $\mathrm{x}$ & .650 \\
\hline $\begin{array}{l}\text { 4. Clear assessment } \\
\text { guidelines }\end{array}$ & $\mathrm{x}$ & .692 & & .631 & & 642 & & .731 & & .578 \\
\hline $\begin{array}{l}\text { 5. Clear learning } \\
\text { expectations }\end{array}$ & $\mathrm{X}$ & .661 & $\mathrm{x}$ & .580 & .656 & & $\mathrm{x}$ & .628 & & .741 \\
\hline
\end{tabular}

This two factor solution is contrary to Barrie et al. (2015) which identified three factors, namely 'motivators', 'assessment', and 'resources' when implementing ASLE with only chemistry students. The sample size of the data and methodology used by Barrie et al. (2015) was rigorous. However, we note that of the three factors identified, the 'motivators' factor had seven survey items, the 'assessment' factor had two survey items, and the 'resources' factor had three survey items. Factors identified with four or more survey items are generally considered reliable, and factors of three survey items or two survey items are generally only considered 
reliable if there is a strong theoretical basis (Field, 2000). However, the factors in this study do have more than four survey items in them with 'experiment based motivators' containing six survey items, and 'course level resources' containing five survey items. Furthermore, on closer scrutiny, it appears that the 'assessment' and 'resources' factors could combine forming 'course-level resources'.

\section{Correlations of the factors and survey items of the ASLE}

\section{Weighting of survey items}

The last survey item, Q14 probes students self-assessment of their 'overall learning experience'. The responses to Q14 demonstrate experiences that range from 'A: excellent' to 'E: very poor'. They can be analysed in two ways. The first method uses a ratio of positive to negative responses, where positive (A and $\mathrm{B}$ ) responses were treated equally, as were negative (D and E) responses. The second method scales the responses on a -2 to 2 scale, with the extreme responses ( $\mathrm{A}$ and $\mathrm{E}$ ) being given twice the weight of responses $\mathrm{B}$ and $\mathrm{D}$. This method contains the value judgement that $\mathrm{A} / \mathrm{E}$ and $\mathrm{B} / \mathrm{D}$ are equally weighted but opposite in value, and that $\mathrm{A} / \mathrm{E}$ are valued doubly compared to $\mathrm{B} / \mathrm{D}$. It was found that the two methods of analysis gave similar results, but the second method gave a better spread of results and separation of scores. The first method would bunch the data at the extremes of the measuring scales. These trends were observed for Likert style questions. For these reasons the second method was selected to use in this study.

\section{The two factors with respect to the overall score}

For each factor, the scores for the individual survey items that make up that factor were averaged and plotted against the 'overall learning experience' score for each individual experiment. The results are plotted in Figure 1. Both factors, 'experiment-based motivators' and 'course-level resources', correlate well with the overall score. The 'experiment-based motivators' factor is more tightly clustered than the 'course-level resources' factor. However, the $R^{2}$ value of the 'experiment-based motivators' factor is lower. This is due to one outlier that only had 13 responses compared to an average response frequency of 117. Although it is likely that the large variance of this experiment is due to random chance, there is no obvious reason to discard this data point. Without this data point the $R^{2}$ value of the 'experiment-based motivators' factor increases to 0.86 .

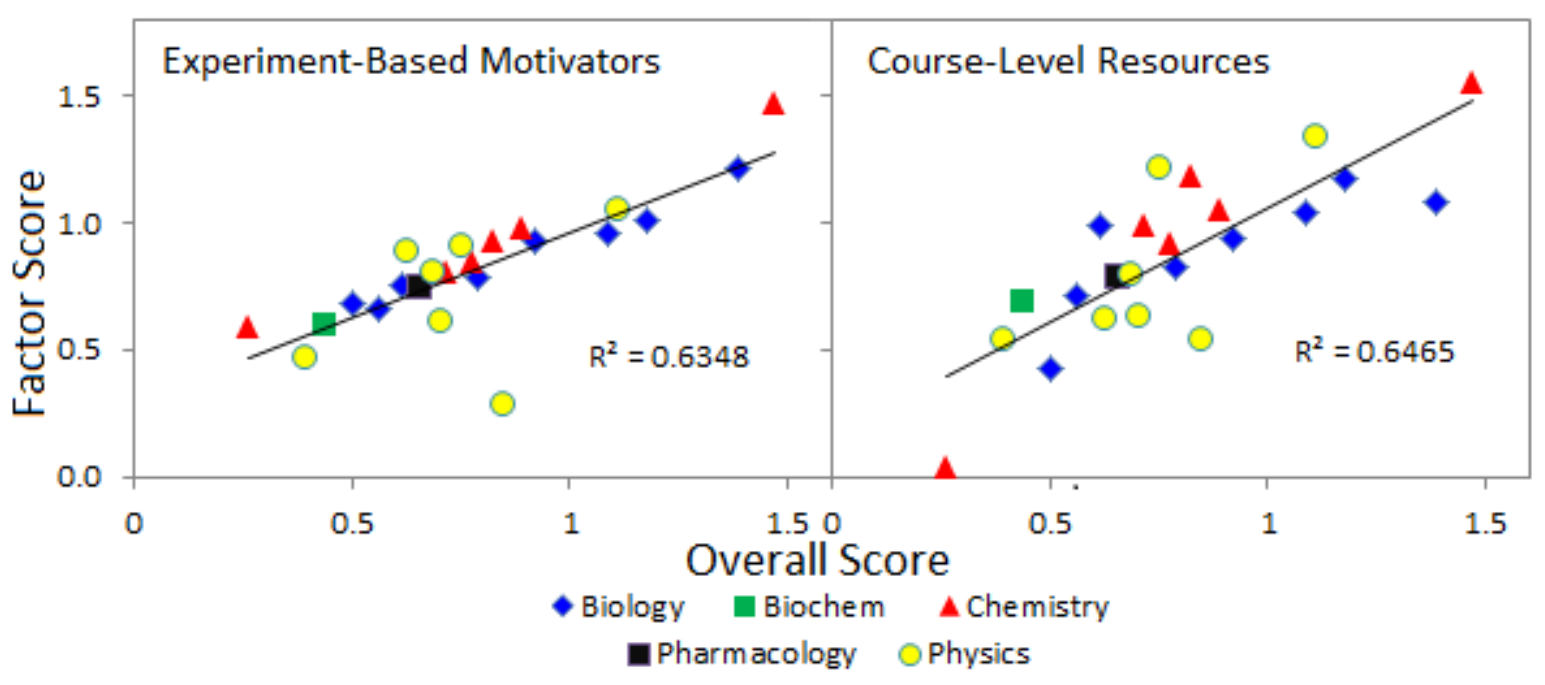

Figure 1: Average factor scores for the two extracted factors plotted against the overall score. 
The survey items of the 'experiment-based motivators' factor with respect to the overall score

In Figure 2 the 'experiment-based motivators' factor is unpacked into individual survey items, and the average score is plotted against the overall score. The survey items of 'interest' and 'increased understanding' correlate very well with the overall score, with a moderate correlation for 'relevance'. The relevance of these survey items to laboratory learning is supported by a previous study that surveyed both student and teacher perceptions of laboratory work in secondary schools (Wilkinson \& Ward, 1997). In that work both students and teachers reported that the main aim of laboratory work was to make science more interesting and enjoyable through actual experience.

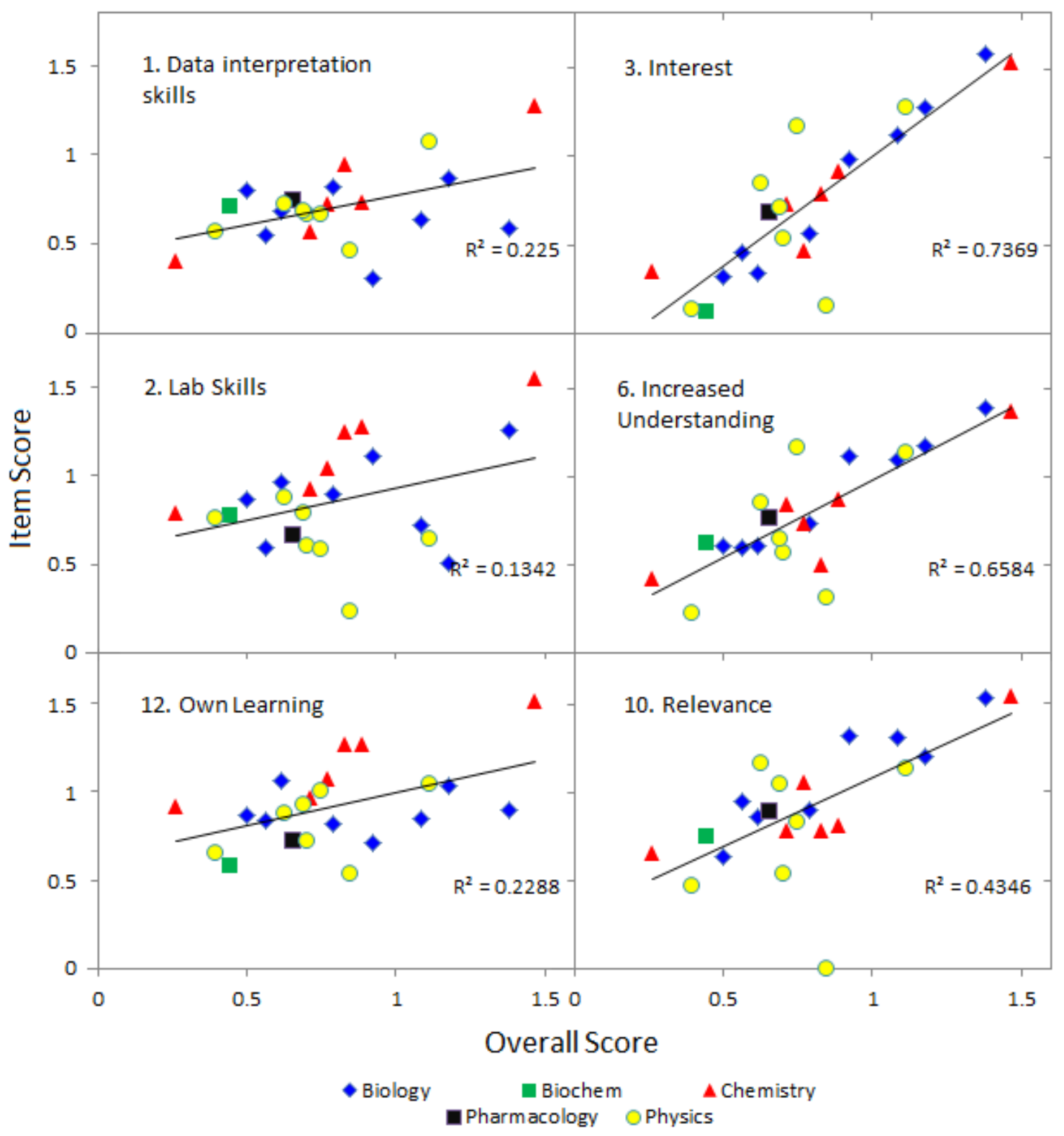

Figure 2: Scores of individual survey items of the 'experiment-based motivators' factor plotted against the overall score. 
The other survey items, 'data interpretation skills', 'lab skills' and 'responsibility for own learning' are more skills based as opposed to the previous three survey items which are more content based, and are not as well correlated to overall learning experience. This indicates that across the science disciplines, the amount of interest in and understanding that can be gained through an experiment are the most important influences to a student's overall learning experience. These relationships are clear across biology, physics, and chemistry, although the data points for physics are somewhat more spread than biology and chemistry.

The survey items of the 'course-level resources' factor with respect to the overall score The individual survey items of the 'course-level resources' factor are unpacked in Figure 3 (a) and (b). The survey items from the 'course-level resources' factor were moderately correlated to the overall score. The two survey items that were best correlated to the overall score were the two that are related to assessment, as was found by Barrie et al., (2015) for chemistry. Furthermore, Barrie et al. (2015) had observed that the survey items 'background material', demonstrators', and 'lab notes' followed a pattern of a linear increase up until an overall score of 1 or 'good', after which the scores would level off. Figure 3 (c) highlights the data points that correspond to an overall score $>1$ and a similar levelling off pattern can be observed. This indicated that the levelling off pattern is not unique to chemistry, but common to all disciplines. 
(a)

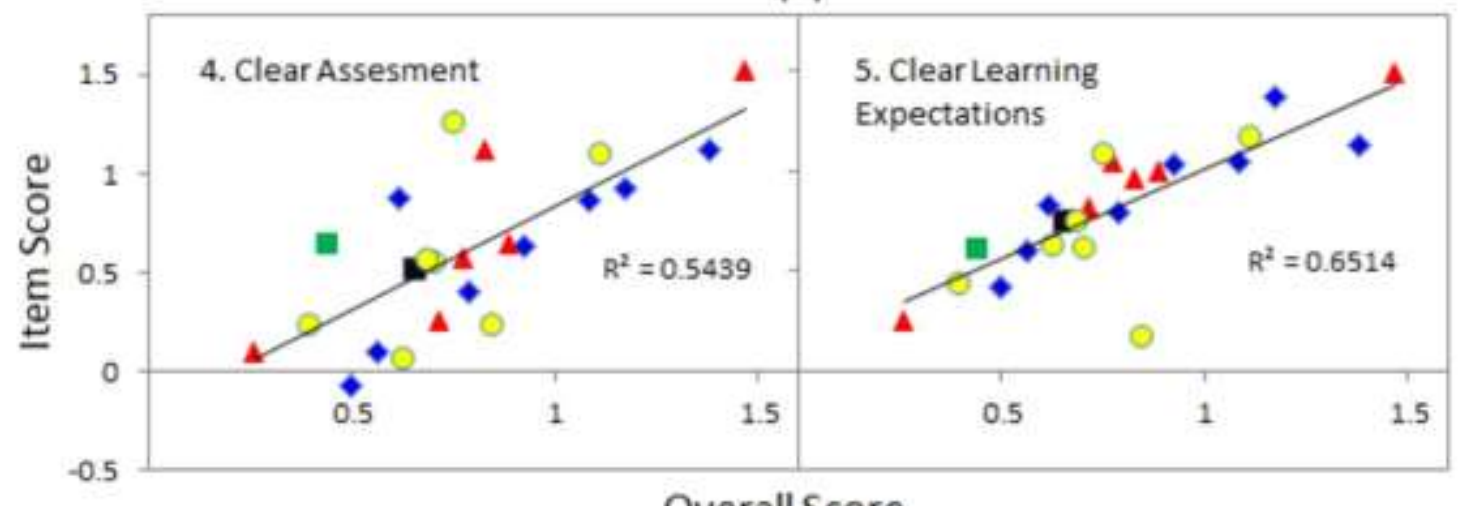

(b)

(c)

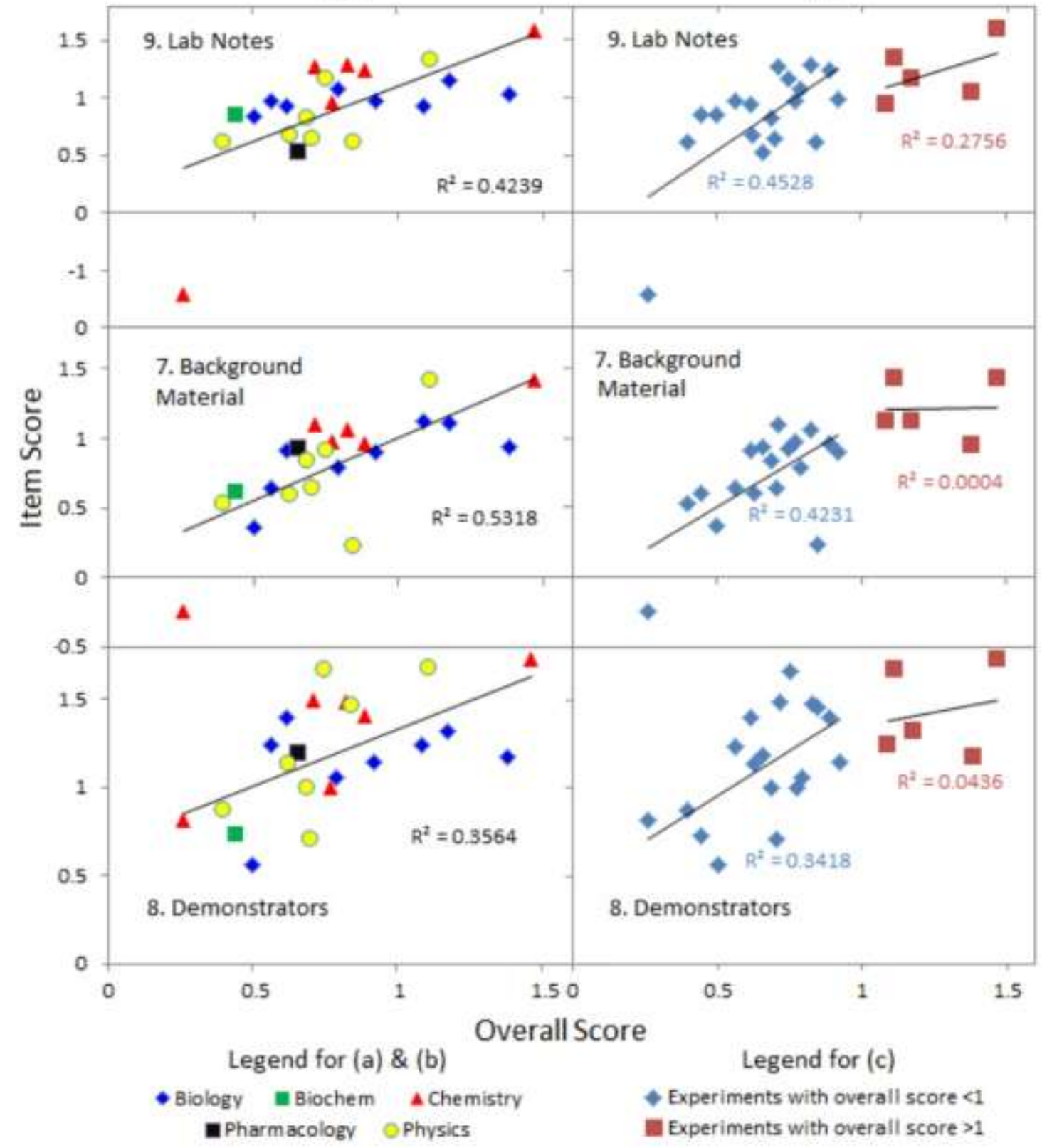

Figure 3: Scores of individual survey items of the 'course-level resources' factor plotted against the overall score. 


\section{Extracted factor correlations to 'motivation-hygiene' theory}

The motivation-hygiene theory was initially based around the motivation of employees in the workplace (Herzberg, 1968), and since its inception has been mainly implemented in industrial and organisational psychology (Eisenberg, Goodall, \& Trethewey, 2007; Miller, 2006; Papa, Daniels, \& Spiker, 2008). Despite the considerable difference between this context and that of students in a laboratory, we can still draw comparisons between the survey items in the factors extracted in this study and the survey items identified by the motivation-hygiene theory. There are several points of contention, for example are the two factors truly independent, are these factors influenced by expectations. However, the two factor theory of motivation persists in various guises amongst education practitioners as it explains intrinsic motivations (Katt \& Condly, 2009). In Table 5 survey items identified in this study are compared to those originally identified by Herzberg (1968).

Table 5: Comparison of survey items from the ASLE survey to those originally identified by Herzberg (1968). *Note that 'teamwork' did not load with either factor in this study and was removed from the factor analysis.

\begin{tabular}{|l|l|l|l|}
\hline $\begin{array}{l}\text { Course-based } \\
\text { resources }\end{array}$ & $\begin{array}{l}\text { Hygiene (Hertzberg, } \\
\text { 1968) }\end{array}$ & $\begin{array}{l}\text { Experiment-based } \\
\text { motivators }\end{array}$ & $\begin{array}{l}\text { Motivators } \\
\text { (Hertzberg, 1968) }\end{array}$ \\
\hline $\begin{array}{l}\text { Lab Note / } \\
\text { Background } \\
\text { Material }\end{array}$ & $\begin{array}{l}\text { Company policy } \\
\text { administration }\end{array}$ & $\begin{array}{l}\text { Data interpretation / } \\
\text { Lab skills }\end{array}$ & Achievement \\
\hline $\begin{array}{l}\text { Demonstrator } \\
\text { Supervision }\end{array}$ & Supervision & $\begin{array}{l}\text { Responsibility for } \\
\text { own learning }\end{array}$ & Responsibility \\
\hline $\begin{array}{l}\text { Demonstrator } \\
\text { Supervision }\end{array}$ & $\begin{array}{l}\text { Relationship with } \\
\text { supervisors }\end{array}$ & Interest & Work Itself \\
\hline $\begin{array}{l}\text { Clear Learning } \\
\text { expectations }\end{array}$ & Work conditions & Relevance & Recognition \\
\hline Teamwork & $\begin{array}{l}\text { Relationship with } \\
\text { peers }\end{array}$ & $\begin{array}{l}\text { Increased } \\
\text { Understanding }\end{array}$ & Growth \\
\hline
\end{tabular}

Essentially the motivation factor is related to the nature of the work which is related to achievement, competency and processes. When applied to students learning in undergraduate science experiments, these could correspond to survey items such as 'laboratory skills', 'interest in experiment', and 'relevance of experiment to discipline'. The maintenance factor is related to the environment, procedures and supervision and could contain survey items such as 'laboratory notes', 'clear learning expectations', and 'demonstrator supervision'. Note that 'teamwork' was not found to belong to either factor in this study, and 'relationship to peers' was also found by Herzberg (1968) to only be slightly more correlated towards the hygiene factor compared to motivators factor.

\section{The survey items that do not load; time and teamwork}

There were two survey items, Q11 'teamwork' and Q13 'time', that did not group with any other survey items and were removed from the factor analysis due to strong self-correlation. The average scores for these survey items are plotted against the overall score in Figure 4. It is evident that there is no significant correlation between these survey items and the overall score. A similar result was found by (Barrie et al 2015), suggesting that the result found in chemistry possibly extends to other science disciplines. 


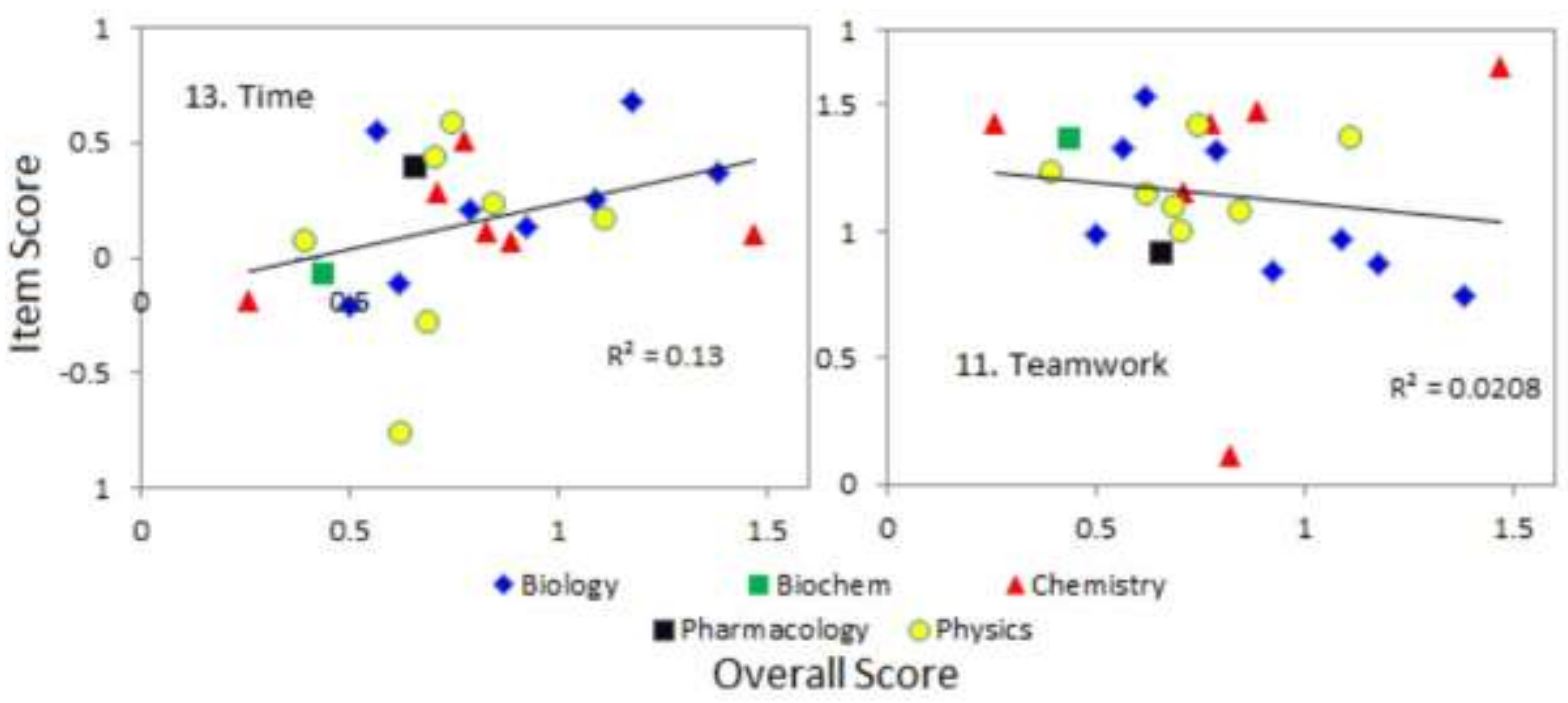

\section{Figure 4: Scores of individual survey items of 'time' and 'teamwork' factor plotted against the overall score}

This result is informative to educators as there is often an emphasis on using laboratory experimentation in order to teach graduates teamwork skills. This study suggests that while this might be useful and helpful for graduates, it does not factor into their overall perception of a laboratory experiment. When looking at the graph for the 'time' survey item, the majority of experiments were rated as having a positive $>0$ response, with only six of the 23 experiments being given a negative response. This indicated that for most of the laboratory experiments in this study, there was adequate time. All of the experiments that had a negative 'time' score corresponded to experiments that have a below average overall score. These results indicate that having adequate time is appreciated by students, but having more time than is necessary does not greatly impact their overall opinion of the experiment they performed. This result is supported by another study which used the ASLE instrument (Southam et al., 2013) over the course of several years for a specific chemistry experiment. There was no statistically significant difference in the 'overall' score given between students who reported that there was sufficient time and those who did not.

\section{Discussion}

\section{Implications for teaching practitioners and for research}

The two factors extracted from the survey data, 'experiment-based motivators' and 'courselevel resources' highlight the two main ways students perceive their lab experiments. These factors also appear to correlate to the factors described in the 'motivation-hygiene' two factor theory described by Herzberg (1968). This result suggests that educators should reflect on the experiments they offer and evaluate them with a focus on these two factors. It also suggests that research on motivation in the workplace can be applied to the student laboratory experience. By understanding how our students perceive the experiments they perform we can hone our teaching to increase student engagement and understanding. The role of the demonstrator (Lees, 2002) needs further investigation. A more in-depth look at staff and demonstrator perceptions would also be valuable to shed light on why this survey item did not correlate well with the students' overall perception of the experiment. 
This survey provides a simple instrument for those invested in improving student perceptions of laboratory experiments (Schumacher, 2007) and Chemistry Education: Research and Practice (Read \& Kable, 2007)). It can be used to compare and contrast the efficacy of lab experiments and possibly programs across the various science disciplines. Ongoing research and deliberation on the goals of experimental programs (Boud et al., 1986; Hart et al, 2000; Abraham \& Millar, 2008; Hofstein \& Lunetta, 2004; Hofstein \& Mamlok-Naaman, 2007), have identified the difficulty associated with ascertaining the efficacy of the lab learning environment. In this regard, the ASLE provides a relatively easy, practical and useful measure of student experiences. The measure can be used to benchmark different experiments and improve the quality of student experiences within the laboratory program over time. The examination of the survey items can be used to identify and improve facets of individual experiments.

This means that academics from different disciplines can use the same language to channel resources in a concerted manner, and develop faculty wide initiatives for laboratory learning. Employers are interested in science specific skills, and as academics we must ensure that students develop these skills and are being prepared for the workforce, whichever discipline they chose to study. This is particularly important in view of reports which articulate that employers are interested in survey items measured in the ASLE (Harris, 2012; Royal Australian Chemical Institute, 2005). ASLE demonstrates that students self-report experiencing these skills and are discerning about what they think is a good learning experience. This is the first step towards understanding how students experience these skills. The next step would be to measure the development of those skills.

\section{Limitations of this study}

It is important to take note of the limitations of this study. All of the experiments included were from Australian universities, and the majority of these were first year courses. Different countries or cultures could have differing teaching and learning styles, which may result in alternative conclusions about this survey instrument. Senior students may also place a different emphasis on what are the most important features of experiments for good learning experiences. Consequently, further research is necessary across different countries and year levels. We also note a New Zealand study that found direct questioning of students resulted in them overestimating the strength of their opinions (Borrmann, 2008), in similar laboratory conditions to this study. Additionally, the fact that the data came from many different lab programs across multiple institutions and disciplines meant that the format of the laboratory notes could not be controlled. The level of 'open inquiry' in laboratory programs/notes has a substantial effect on the outcomes of the program, and this could also be impacting the results (Yakar \& Baykara, 2014, Furtak, Seidal, Iverson, \& Briggs, 2012).

\section{Conclusions}

The laboratory learning components of undergraduate science courses are considered to be a very important component of student learning. Despite the general importance that is placed on laboratory learning by educators, which elements of the laboratory experience are the most valuable to students is not well understood. A sample of 2691 students were surveyed using the ASLE instrument. These students came from, physics, chemistry, biology, biochemistry and pharmacology disciplines. The results of the survey identify what elements students perceive as the most important in the laboratory setting. The correlation between all individual survey items and the 'overall learning experience' rating of the experiment was explored. This revealed the survey items of 'interest' and 'increased understanding' as the two survey items 
that had the best correlation with the experiment's 'overall' rating. In contrast, the survey items 'time' and 'teamwork' were found to have the poorest correlations with the 'overall' rating of the experiment.

An exploratory factor analysis was used to analyse student responses. There were two survey items which self-correlated and were removed from the factor analysis. These were, having sufficient 'time' to complete the experiment, and the benefits of 'teamwork' from working in a group. Two factors were extracted by the factor analysis, with the first factor being identified as 'experiment-based motivators'. This included survey items such as 'interest', 'relevance' or gaining 'increased understanding'. The second factor was identified as 'course-level resources', with survey items such as 'laboratory demonstrators (tutor/TA)', 'lab notes', or 'clear assessment'. These factors persisted across all disciplines, with few survey items deviating between the factors extracted from each discipline. These factors also seem to correspond to the 'motivation' and 'hygiene' factors from Herzberg's (1968) dual factor theory. This provides a way for academics from different disciplines to share a common language and develop faculty wide initiatives for improving laboratory learning. Despite the overwhelming similarities between the disciplines, the physics discipline was the most divergent. Discussion of these differences also helps us to bridge the gap and have a crossdisciplinary approach.

\section{Acknowledgements}

The ASELL project would not be possible without the financial support of the Australian Learning and Teaching Council and its predecessors. The project has received ongoing support of the Australian Council of Deans of Science and Faculties of Science across Australia. Our thanks to the many staff and students who assisted in administering, and completing surveys, and to all the academics who collected the data and let us use their classes. Collection of data for this project was approved by the University of Sydney Human Research Ethics Committee.

\section{References}

Abrahams, I., \& Millar, R. (2008). Does practical work really work? A study of the effectiveness of practical work as a teaching and learning method in school science. International Journal of Science Education, 30(14), 1945-1969.

Barrie, S. C., Bucat, R. B., Buntine, M. A., Burke da Silva, K., Crisp, G. T., George, A. V., ... Yeung, A. (2015). Development, evaluation and use of a student experience survey in undergraduate science laboratories: The Advancing Science by Enhancing Learning in the Laboratory Student Laboratory Learning Experience Survey. International Journal of Science Education, 37(11), 1795-1814.

Bassett-Jones, N., \& Lloyd, G. C. (2005). Does Herzberg's motivation theory have staying power? Journal of Management Development, 24(10), 929-943.

Beck, C. W., \& Blumer, L. S. (2016). Alternative realities: Faculty and Student perceptions of instructional practices in laboratory courses. CBE-Life Sciences Education, 15(4), 1-10.

Borrmann, T. (2008). Laboratory education in New Zealand. Eurasia Journal of Mathematics, Science \& Technology Education, 4(4), 327-335.

Boud, D., Dunn, J., \& Hegarty-Hazel, E. (1986). Teaching in laboratories. Guilford, Surrey: Society for Research into Higher Education \& NFER-Nelson.

Burgess, C. A., Yeung, A., \& Sharma, M. D. (2015). Integrating assessment to promote engagement in an introductory chemistry laboratory. International Journal of Innovation in Science and Mathematics Education, 23(2), 74-91.

Dunn, T. J., Baguley, T., \& Brunsden, V. (2014). From alpha to omega: A practical solution to the pervasive problem of internal consistency estimation. British Journal of Psychology, 105(3), 399412. 10.1111/bjop.12046

Eisenberg, E. M., Goodall, H. L., \&Trethewey, A. (2007). Organizational communication: Balancing creativity and constraint, 5th ed, Boston, MA: Bedford/St Martin's.

Field, A. (2000). Discovering statictics using SPSS. London: Thousand Oaks, Calif.: Sage Publications. 
Furtak, E. M., Seidal, T., Iverson, H., \& Briggs, D. C. (2012). Experimental and quasi-experimental studies of inquiry-based science teaching: A meta-analysis, Review of Educational Research, 82(3), 300-329.

George, D., \& Mallery, P. (2003). SPSS for Windows step by step: A simple guide and reference 11.0 update (4th ed.). Boston: Allyn \& Bacon.

Harris K.-L. (2012). A background in science: What science means for Australian society. Centre for the Study of Higher Education, University of Melbourne 2012.

Hart, C., Mulhall, P., Berry, A., Loughran, J., \& Gunstone, R. (2000). What is the purpose of this experiment? Or can students learn something from doing experiments? Journal of Research in Science Teaching, 37(7), 655-675.

Herzberg, F. (1968). 'One more time: How do you motivate employees'. Harvard Business Review, 46(1), 5362.

Hofstein, A., \& Lunetta, V. N. (1982). The laboratory in science teaching: Neglected aspects of research. Review of Educational Research, 52, 201-217.

Hofstein, A., \& Lunetta, V. N. (2004). The laboratory in science education: Foundation for the 21st century. Science Education, 88, 28-54.

Hofstein, A., \& Mamlok-Naaman, R. (2007). The laboratory in science education: The state of the art. Chemistry Education Research and Practice, 8(2), 105-107.

Kaiser, H. F. (1958). The varimax criterion for analytic rotation in factor analysis. Psychometrica, 23(3), 187200.

Katt, J. A., \& Condly, S. J. (2009). A preliminary study of classroom motivators and de-motivators from a motivation-hygiene perspective, Communication Education, 58(2), 213-234.

Lees, B. (2002). Teaching assistants in schools: The current state of play. Slough: National Foundation for Educational Research

Membiela, P., \& Vidal, M. (2017). The interest of the diversity of perspectives and methodologies in evaluating the science laboratory learning environment. Eurasia Journal of Mathematics Science and Technology Education, 13(6), 2069-2083.

Miller, K. (2006). Organizational communication: Approaches and processes, 4th ed. Belmont, CA: Thomson.

Papa, M. J., Daniels, T. D., \& Spiker, B. K. (2008). Organizational communication: Perspectives and trends. Thousand Oaks, CA: Sage.

Read, J.R., \& Kable, S. H. (2007). Educational analysis of the first year chemistry experiment 'Thermodynamics Think-In': An ACELL experiment. Chemistry Education Research and Practice, 8(2), 255-273.

Rice, J. W., Thomas, S. M., \& O'Toole, P. (2009). Tertiary science education in the 21 st century. Sydney: Australian Learning and Teaching Council.

Richardson, A., Sharma, M. D., \& Khachan, J. (2008). What are students learning in practicals? A cross sectional study in university physics laboratories. International Journal of Innovation in Science and Mathematics Education, CAL- laborate International, 16(1), 20-27.

Royal Australian Chemical Institute. (2005). The future of chemistry study: Supply and demand of chemists. from https://www.raci.org.au/document/item/1782

Schumacher, D. (2007). Editorial: Student undergraduate laboratory and project work. European Journal of Physics, 28(3).

Sharma, M.D., Mills, D., Mendez, A., \& Pollard, J. (2005, October 22). Learning outcomes and curriculum development in physics. Retrieved from http://www.physics.usyd.edu.au/super/AUTC

Southam, D. C., Shand, B., Buntine, M. A., Kable, S. H., Read, J. R., \& Morris, J. C. (2013). The timing of an experiment in the laboratory program is crucial for the student laboratory experience: Acylation of ferrocene as a case study. Chemistry Education Research and Practice, 14, 476-484.

Weston, T. J., \& Laursen, S. L. (2015). The Undergraduate Research Student Self-Assessment (URSSA): Validation for use in program evaluation. CBE-Life Sciences Education, 14(3), 1-10.

Wilkinson, J., \& Ward, M. (1997). A comparative study of students' and their teacher's perceptions of laboratory work in secondary schools. Research ion Science Education, 27(4), 599-610.

Yakar, Z., \& Baykara, H. (2014). Inquiry-based laboratory practices in a science teacher training program. Eurasia Journal of Mathematics, Science \& Technology Education, 10(2), 173-183.

Yeung, A., Pyke, S. M., Sharma, M. D., Barrie, S. C., Buntine, M. A., Burke Da Silva, K., Kable, S. H., \& Lim, K. F. (2011). The Advancing Science by Enhancing Learning in the Laboratory (ASELL) Project: The first Australian multidisciplinary workshop. International Journal of Innovation in Science and Mathematics Education, 19(2), 51-72. 